\title{
ENRIQUE DUSSEL: ENTRE LATINOAMÉRICA Y LA HERMENÉUTICA DE LA OTREDAD
}

\author{
Francisco Javier Castillejos Rodríguez \\ Instituto de Posgrado en Derecho-Ciudad de México \\ bttp://dx.doi.org/10.15304/ag.38.1.4417
}

A Valery

\section{Resumen}

El objetivo de este ensayo es exponer los fundamentos de la filosofía de la liberación de Enrique Dussel y explicar sus aportaciones en el contexto del pensamiento latinoamericano. En un nivel postmetafísico de fundamentación, la filosofía de la liberación adopta el ethos del pensamiento semita y la hermenéutica del «Otro» de Levinas con el propósito de formular una crítica al eurocentrismo y edificar un modelo filosófico alternativo. Frente a los paradigmas tradicionales de filosofía e historiografía filosófica, Enrique Dussel desarrolla una nueva arquitectónica para dar cuenta de la especificidad de nuestro pensamiento.

Palabras clave: Latinoamérica, liberación, eurocentrismo, hermenéutica, postmetafísica.

\begin{abstract}
The goal of this essay is to expose the foundations of Enrique Dussel's philosophy of liberation and to explain its contributions in the context of Latin-american thinking. In a postmetaphysical level of foundation, the philosophy of liberation adopts the ethos from semitic thinking and the Levinas' hermeneutics of the "Other» with the proposal of formulate a criticism of eurocentrism and to build an alternative philosophical model. In front of the traditional paradigms of philosophy and philosophical historiography, Enrique Dussel develops a new arquitectonics to report on the specificity of our thinking.

Keywords: Latin-America, liberation, eurocentrism, hermeneutics, postmetaphysics.
\end{abstract}

Recibido: 19/11/2017. Aceptado: 20/12/2017. 


\section{Latinoamérica y la tragedia del «eurocentrismo»}

Después de los clásicos, conviene preguntarse en torno a Enrique Dussel y el pensamiento latinoamericano: Quid sub sole novum? El planteamiento del problema del «lugar de enunciación» (locus enuntiationis) desde el cual se edifican los sistemas filosóficos actuales posee una especial relevancia cuando el tópico a tratar es el referente a la especificidad de la filosofía latinoamericana. En este contexto, como preludio a dicha cuestión será importante señalar algunas de las características manifestadas por el pensamiento filosófico contemporáneo.

Una de las peculiaridades del hoy denominado «pensamiento postmetafísico" (desde el nachmetaphysisches Denken habermasiano hasta el pensiero debole de Vattimo) es su explicitación de la génesis regional de todo pensamiento filosófico ${ }^{1}$. Después de Heidegger y Wittgenstein, el status singular de la era postmetafísica se ha manifestado en la determinación del carácter finito del pensamiento humano y su ubicación histórica: ya sea que los individuos se entiendan como inmersos en el background de los juegos de lenguaje, en su carácter de seres-en-el-mundo en que se sustenta la facticidad del «ser-ahí» (Dasein) o en la pre-estructura de la comprensión propia de su labor hermenéutica, de ahora en adelante los modelos filosóficos -y las teorías sociales respectivas- tendrán una limitación regional-comunitaria de corte prima facie determinante en las concepciones del mundo (Weltanschauungen) correspondientes. Así, la filosofía cuestiona sus pretensiones de universalidad y explicita su contexto espacio-temporal de surgimiento. Para decirlo en términos de John Searle: uno de los grandes desafíos de la autocomprensión de la filosofía contemporánea consiste en explicar el carácter universal de los modelos teóricos que, sin excepción, son el producto de circunstancias y condiciones locales (Searle, 2003: 6). Así, el pensamiento postmetafísico rechaza un concepto universal, trascendental o absoluto de la «razón» y todo lo que ello implica. La ratio, al igual que la concepción

${ }^{1} \mathrm{El}$ «pensamiento postmetafísico» (nachmetaphysisches Denken) constituye un tercer paradigma en una concepción de la historia de la filosofía entendida como una sucesión de tres modelos: 1) el paradigma ontológico (metafísica dogmática pre-epistémica), 2) el paradigma epistemológico (mentalismo o filosofía de la conciencia) y 3) paradigma lingüístico (o modelo "postmetafísico» de pensamiento). Este último paradigma es un producto del «giro lingüístico-hermenéutico-pragmático» propio de la filosofía contemporánea y se caracteriza, sobre todo, por su carácter no-fundacionalista y por su destrascendentalización de los conceptos modernos de «sujeto» y «razón». Sobre esta cuestión, resultan indispensables: (Apel, 2002: 38-45), (Habermas, 1990: 39 ss.), (Rorty, 1979: 263) y (Gadamer, 2007: 11 ss. y 85). 
del «yo» de la filosofía moderna, adquiere un carácter situado, i.e., ubicado regionalmente (Benhabib, 1992: 3-6 y Bernstein, 1983: 2-19).

La idea del «eurocentrismo», i.e., la pretensión de la particularidad europea de considerarse universal sin serlo efectivamente (Dussel, 2004: 297), es producto de este "giro postmetafísico» de la filosofía actual. Epistemológicamente hablando, el pensamiento filosófico de Enrique Dussel puede correctamente ser colocado -al lado de autores como Laclau, Mouffe, Badiou o Lefort- en el círculo del "postheideggerianismo de izquierda», i.e., en aquella concepción no-fundacionalista que ha cuestionado fuertemente las figuras metafísicas tradicionales de totalidad, universalidad, esencia y fundamento, pero con una orientación ideológica distinta a la de su expositor original $^{2}$. Las consecuencias de dicha categorización son evidentes: la aceptación de un modelo agonístico sostenido tanto en el heteromorfismo como en la supuesta inconmensurabilidad de los juegos del lenguaje y formas de vida presupone el concepto de sospecha como paradigma de las construcciones teóricas (Lyotard, 2008: 10 y Vattimo, 1994: 10). En esta dirección, la filosofía de la liberación de Dussel asume, desde sus propios cimientos, la exigencia de desenmascarar todas aquellas particularidades «encubiertas» que querrían hacerse pasar por la totalidad. En su polémica contra Apel y Habermas, enfatiza Dussel ad pedem litterae:

Pienso que puede afirmarse que ninguna eticidad (Sittlichkeit) será nunca postconvencional, y que toda moral universal (aun la de Apel o Habermas) siempre se articula de hecho a una eticidad convencional dada [...]. Es ingenuo pensar que hoy el filósofo crítico europeo pueda situarse en su vida cotidiana postconvencionalmente, no advirtiendo que sus «reacciones» concretas siguen siendo las de un miembro de la cultura occidental (Dussel, 2004: 298).

La importancia de la explicitación del «eurocentrismo» sale a la luz cuando se trata el problema del pensamiento latinoamericano. En primer lugar, permite entender la historia de la filosofía desde una perspectiva distinta. En oposición a los modelos tradicionales ${ }^{3}$, Dussel propone entender el desarrollo de la filosofía a través de un «modelo mundial», i.e., mediante el reconocimiento de una diversidad de tradiciones regionales filosóficas

${ }^{2}$ Es necesario recordar que para muchos autores contemporáneos, Heidegger es el último filósofo reconocible universalmente. En este sentido: (Badiou, 1999: 9). Sobre el concepto de "postheideggerianismo de izquierda» y su relación con el pensamiento postfundacional actual puede verse: (Marchart, 2009: 14 ss.) y (Vattimo, 2010: 49-53).

${ }^{3}$ Dussel nombra al modelo «ario» (romántico-alemán) que parte de los griegos, por un lado, y el modelo "antiguo» (de Heródoto, Platón y Aristóteles) que comienza con los egipcios africanos (Dussel, 1998a: 43). En el ámbito específico de la filosofía política, Dussel 
que girarían en torno a un bloque bien definido de «núcleos problemáticos universales» respecto del cual el pensamiento europeo constituiría una instanciación y no un paradigma (Dussel, 2009a: 15-19 y 2010b: 120-121). En segundo lugar, y como consecuencia directa de lo anterior, hace posible determinar la relevancia de la periferia -y, en particular, de Latinoamérica- en la historia mundial. El hecho de pasar de una filosofía de la presencia propia de la tradición metafísica de Occidente a una filosofía de la diferencia ${ }^{4}$ hace posible establecer, como requerimiento metateórico de las construcciones intelectuales regionales, la exigencia de abordar las propias problemáticas-sociales, económicas, políticas-aún con el riesgo de exhibir cierta inconmensurabilidad respecto a las Weltanschaunngen europeas. Se trataría, en este contexto, de tomar en serio el locus enuntiationis del pensar filosófico.

Si bien la filosofía de la liberación de Dussel es congruente con el "postheideggerianismo de izquierda», su pretensión crítica le obligó, en su momento, a dar un paso más allá de la simple explicitación de una razón situada. De igual manera que otros célebres pensadores contemporáneos Jaques Derrida y Bernhard Waldenfels son algunos de ellos-, la concepción dusseliana se vio fuertemente influenciada por un autor que es considerado, hic et nunc, como el último gran crítico de la metafísica occidental: Emmanuel Levinas. Veamos en qué sentido.

\section{La hermenéutica de la otredad. Levinas y el «nuevo pensamiento» latinoamericano}

La metafísica precede a la ontología Emmanuel Levinas

La necesidad de introducir nuevas categorías que hicieran posible una superación crítica del eurocentrismo y no sólo su explicitación fue cubierta recurriendo al pensamiento del filósofo lituano Emmanuel Levinas. El autor

critica seis características de los paradigmas contemporáneos: su helenocentrismo, su occidentalismo, su periodización tradicional -Antigüedad, Medievo y Modernidad-, su conceptuación secular, el colonialismo mental de los filósofos periféricos y, por supuesto, su evidente eurocentrismo. Para el desarrollo de estos tópicos, véase: (Dussel, 2007a: 11 ss.). Sobre el problema de la centralidad europea, su desprecio por otras culturas y su correspondiente historiografía manifestada en una "trayectoria eurocéntrica», resultan bastante interesantes: (Joseph, 2009: 30-31) y (Mazrui, 2009: xi-xiv).

${ }^{4}$ Sobre esto, consúltese: (Derrida, 1971: 7 ss.) y (Hall, 2000: 75). 
de Totalidad e infinito. Ensayo sobre la exterioridad proporcionó a la filosofía de la liberación un arsenal conceptual ad hoc para la constitución de una ética y una filosofía política críticas. Tomando como punto de partida la originaria contraposición entre totalidad y exterioridad, Levinas daba a la tradición metafísica de Occidente un golpe mortal:

Filosofía del poder, la ontología, como filosofía primera que no cuestiona el Mismo, es una filosofía de la injusticia. [...Lleva] fatalmente a otra potencia, a la dominación imperialista, a la tiranía. [...] El ser antes que el ente, la ontología antes que la metafísica, es la libertad (aunque de la teoría) antes que la justicia. Es un movimiento en el Mismo antes que la obligación frente al Otro. Es necesario invertir los términos (Levinas, 1977: 70-71).

Influenciado por la quinta de las Meditaciones Cartesianas de Husserl y con un desarrollo teorético congruente con la crítica al paradigma solipsista de la conciencia efectuada en términos del pensamiento postmetafísico, Levinas introdujo las categorías de «exterioridad» y «otredad» como un recurso para dar cuenta del ocultamiento trans-ontológico llevado a cabo por la metafísica occidental. De ahora en adelante, no sería el ser el que ocuparía el primado metafísico, sino el «Otro», quien no es ser, sino trascendencia de $\operatorname{ser}^{5}$ (Dussel, 2010a: 370 y Medina, 2010: 10 y 173).

La superación trans-ontológica de la totalidad como un abandono a la «lógica de la violencia» de la tradición metafísica parte, así, de la exterioridad que surge de las exigencias del «Otro». En Levinas "aparece la figura extraordinaria del Otro que funciona como un correctivo permanente que irrumpe en los órdenes existentes y los pone en tela de juicio" (Waldenfels, 2010: 40). En este contexto, la edificación levinasiana de la alteridad rompe con la pretensión imperial de la filosofía occidental de reducir el Otro al Mismo y fundamenta un pensamiento de trascendencia: frente al primado de la ontología opone el de la ética. La hermenéutica de la otredad no es algo diferente a una «ética en torno al Otro» (Grondin, 2006: 376 y Van Riessen, 2007: 18 y 26).

La idea de un «nuevo pensamiento» de la diferencia y la alteridad expresión acuñada por Franz Rosenweig-, pero aplicada in primis a un contexto específicamente latinoamericano, es un mérito que corresponde,

${ }^{5}$ Es necesario precisar que Levinas emplea la expresión «ontología» para referirse a la tradición metafísica de Occidente -con sus referencias al ser y a la totalidad-, mientras que «metafísica» se reserva para señalar el pensamiento que, al abrirse al más allá ontológico (metà ta physikà), es característico de la alteridad y que escapa de la lógica de la violencia propia de la categorización tradicional (Vattimo, 2001: 76). Para una crítica a esta concepción, véase: (Derrida, 1989: 113 y 189-193). 
inter alia, a la filosofía dusseliana de la liberación (Scannone, 2005: 104105). Como una reacción a la «totalización de la totalidad» producto de las Weltanschauungen eurocéntricas, Dussel encontraría en la categoría de otredad el nuevo punto de partida para hacer una crítica a las pretensiones imperiales del Viejo Mundo. Pero, aun siendo un levinasiano convencido, Dussel tropezaría con un problema: la ética de Levinas no podía articular un concepto de "política» de manera positiva (Dussel, 2007b: 256-259). Esta imposibilidad de pensar la positividad allende la negatividad condujo a la filosofía de la liberación a pensar «con» Levinas «más allá» de Levinas.

\section{3. ¿Jerusalén o Atenas? La búsqueda de un nuevo punto de partida}

Una de las características de las historias de la filosofía convencionales es su evidente helenocentrismo, i.e., su constante referencia a Grecia como el locus de origen de la filosofía mundial ${ }^{6}$. Partiendo de sus experiencias en contextos vitales semitas no-occidentales, Dussel propone hacer una deconstrucción de la historia de la filosofía que implique ir más allá del helenocentrismo:

Para la reconstrucción de una filosofía latinoamericana era necesario «de-struir» el mito griego. Para comprender la cultura del pueblo latinoamericano era necesario partir de Jerusalén más que de Atenas. Jerusalén hablaba de la dignidad del trabajo, de la posibilidad de la revolución de los pobres; Atenas hablaba de la dignidad de los nobles libres, de la imposibilidad de la emancipación de los esclavos (Dussel, 1998b: 17).

La oposición entre Atenas y Jerusalén representa una instanciación de aquella más general existente entre el pensamiento «indoeuropeo» (un mito para Dussel) y el pensamiento «semita». El primero -que parte desde Grecia y que abarca la modernidad europea por lo menos desde Descartes hasta Hegel- se caracteriza por ser una filosofía de la presencia; el segundo -particular del judío, el cristiano y musulmán-, por ser una filosofía de la diferencia.

El pensamiento «indoeuropeo» se basa en una ontología dualista -cuerpo $v$ s. alma- y en una metafísica fundacionalista desarrollada en torno a la categoría de unidad. La inmortalidad del alma se sostiene sobre una plata-

${ }^{6}$ Dussel señala que la «invención» de Grecia como origen del pensamiento occidental con la correspondiente destitución del Egipto africano- fue obra de los románticos alemanes (Winckelmann, Goethe, Humboldt, Schlegel y Hegel) cuya construcción no pasa de mediados del siglo XIX. Véase: (Dussel, 2004: 224). 
forma que da una prioridad ética y ontológica a lo no-corporal. De manera radicalmente opuesta, el pensamiento «semita» queda edificado sobre una ontología unitaria de la corporalidad expresada en la idea de la resurrección de la carne y en una lógica de la diferencia. De manera consecuente con sus propios fundamentos, ambos tipos de pensamiento llevan a planteamientos éticos substancialmente distintos. El ethos indoeuropeo se proyecta en una moralidad formal que consolida la eticidad existente. La ética indoeuropea aparece, así, equivalente a una lógica de la totalidad: justifica el statu quo mediante la negación de la corporalidad y la exclusión de los pobres, de las «víctimas». El ethos semita da lugar, en cambio, a una ética crítica que parte de los excluidos de la totalidad, i.e., los pobres y los esclavos, y que asume como criterio fundamental la protección de la corporalidad carnal y sus necesidades -hambre, sed, alojamiento, etc.-. Como tal, prevé como posibles los movimientos de liberación (liberation, Befreiung) para la superación de una eticidad injusta ${ }^{7}$. El capítulo 125 del Libro de los muertos, así como las referencias bíblicas a Isaías 58, 7 y Mateo 25,35 ilustran la especificidad ética del pensamiento semita (Dussel, 1998a: 635).

La dimensión normativa implícita en el ethos semita constituye el background universalista de la filosofía de la liberación dusseliana. Elaborada originalmente desde el locus latinoamericano, adquirió conciencia de su status universal al explicitar que las necesidades fundamentales propias de Latinoamérica son, al mismo tiempo, las necesidades de todos los pueblos. El cristianismo y su fundador Jeshúa de Nazareth -y no así la «cristiandad» institucional basada en una antropología dualista- abrieron el proyecto de un reino escatológico a todos los pueblos más allá del horizonte de Israel (Dussel, 1969: 125 y 2007a: 73). En este sentido, la exigencia de universalidad -y todo lo que ella lleva consigo: dignidad, inviolabilidad de la persona, etc.- no fue un «descubrimiento» occidental y particularmente kantiano, sino que correctamente puede ser referido al pensamiento semítico-mesiánico de Jeshúa ${ }^{8}$.

${ }^{7}$ Esta diferenciación está ampliamente expuesta en: (Dussel, 1998a: 25-38).

${ }^{8}$ Sobre la relación de la filosofía de la liberación con el cristianismo, véase: (Barber, 1998: 22 ss.). La célebre definición de Boecio según la cual Persona est naturae rationalis individua substantia (una sustancia individual de naturaleza racional) se coloca en la tradición del cristianismo. A esta le corresponde el mérito de haber desarrollado el problema de la dignidad humana de manera distinta a los modelos antiguos. La perspectiva cristiana rompió con el concepto de dignitas como "participación del hombre en el lógos» -tal como se desarrolla, por ejemplo, en el pensamiento de Cicerón-, fundando la idea de dignidad humana como algo que es propio del hombre en cuanto hombre. Si todos los hombres han 
Sobre la plataforma establecida por el pensamiento de Levinas y el ethos semita, Dussel determina que las categorías fundacionales de una filosofía crítica son las siguientes: 1) La Totalidad representada por el «reino» de este mundo y 2) la Exterioridad simbolizada como trascendencia horizontal de la temporalidad histórica (Dussel, 2007a: 75). En oposición con las éticas ontológicas de la totalidad basadas en el "principio de opresión" (principium oppresionis) y frente al déficit de las morales formales de la universalidad -Kant, Apel, Habermas- desenvueltas bajo un "principio de exclusión» (principium exclusionis), la filosofía de la liberación de desarrolla como una «lógica de la alteridad» cuyo criterio normativo central es la exterioridad del «Otro», i.e., el pobre, el obrero, la mujer oprimida, la raza no blanca, los indígenas, las colonias del imperialismo, etc. (Dussel, 2009b: 44 y Schelkshorn, 1992: 69).

Este modelo de filosofía crítica ha servido a Dussel para plantear el problema del pensamiento latinoamericano, pero asumiendo al mismo tiempo las pretensiones de universalidad de este último. En su ataque a la historiografía convencional en torno al problema de la modernidad, la filosofía de la liberación denuncia el ocultamiento a que fue sometida América Latina por parte del paradigma eurocéntrico. Enfatiza Dussel sobre el particular:

El ego cogito (del Descartes de 1637) no fue la expresión filosófica originaria de la Modernidad. Antes, el ego conquiro (el «yo conquisto» en primer lugar con Hernán Cortés en 1519 en México) debió hacer la experiencia práctica de la «centralidad» europea, de su superioridad, que quedó expresada en la disputa también filosófica de Valladolid de 1550 (Dussel, 2004: 223).

sido creados por Dios a su imagen y semejanza (Génesis 9,6), entonces la vida de cada ser humano es inviolable para los demás seres humanos. Por esta razón, el cristianismo fue el primero en concebir la dignitas en términos de libertad individual y de inviolabilidad de la vida individual. Esta concepción de la persona parte del dogma trinitario propio de la cristología según el cual la «enhipóstasis» de la humanidad de Jesús con el lógos consiste en su participación en la relación de Hijo a Dios padre. El siguiente paso fue entender dicha participación de la personeidad enhipostática de Cristo en términos universalistas, i.e., aplicada también a la personeidad de todo hombre: el ser-persona (Personsein) es la esencia de la dignidad del individuo humano. En el pensamiento moderno, Kant es a quien corresponde el mérito de haber desarrollado este concepto de Person en términos francamente ilustrados: la personalidad (Persönlichkeit) es la libertad e independencia respecto de la naturaleza y, al propio tiempo, la facultad de un ser sometido a leyes puras prácticas que le son propias. Sólo el hombre es un Zweck an sich selbst (fin en sí mismo): el sujeto de la ley moral que representa la Autonomie de la voluntad. En este sentido, la acuñación del concepto de "persona» en la tradición kantiana -por lo menos hasta Rawls y Habermas- puede ser correctamente entendida como una secularización de las categorías cristianas respectivas. Sobre este conjunto de interesantes cuestiones puede consultarse: (Pannenberg, 2002: 129-133). 
La filosofía crítica, en este contexto, tiene como principal función mostrar «la otra cara de la modernidad», i.e., el encubrimiento del «Otro» efectuada desde el descubrimiento de América y la opresión tanto teórica como práctica a que dio lugar (Dussel, 1995: 12 y 119). La historia de la conquista del Caribe, el nacimiento del mestizo y la esclavitud del afro-americano constituyen la génesis misma de la modernidad, i.e., la experiencia ontológica desde donde se entiende la nueva filosofía europea. La justificación de la conquista, por un lado, y la defensa de la otredad del indio americano, por otro, integraron el telón de fondo del origen de la filosofía de la modernidad. Ginés de Sepúlveda, Francisco de Vitoria, Francisco Suárez y Bartolomé de las Casas fueron los primeros filósofos modernos y no Descartes, Hobbes o Spinoza9 (Dussel, 2007a: 13 y 194). En su clásica Filosofía de la liberación de 1977, Dussel subrayaba de manera tajante:

La filosofía de la liberación es reciente. Sin embargo, sus antecedentes son aún más antiguos que la filosofía moderna europea. [...] Contra la ontología clásica del centro, desde Hegel hasta Marcuse, por nombrar lo más lúcido de Europa, se levanta una filosofía de la liberación de la periferia, de los oprimidos, la sombra que la luz del ser no ha podido iluminar. Desde el no-ser, la nada, el otro, la exterioridad, el misterio de lo sin-sentido, partirá nuestro pensar. Es entonces una "filosofía bárbara» (Dussel, 1977: 18 y 23).

La filosofía de la liberación alcanzó dimensiones sofisticadas en términos de una «ética de la liberación»-devenida bastante célebre por su confrontación con la ética discursiva (Diskursethik) de Karl-Otto Apel- y de su respectiva "política de la liberación» en sus versiones tanto históricas como arquitectónicas. En su primera vertiente, Dussel fundamentó el principio material universal que toda ética debía cumplir desde sus mismos presupuestos, i.e., el principio de obligación de producir, reproducir y desarrollar la vida humana concreta de cada sujeto ético de la comunidad ${ }^{10}$ (Dussel, 1998a: 91). En su segunda vertiente, la filosofía de la liberación edificó un concepto positivo de política -en oposición a la ética levinasiana- fundamentado en tres principios normativos implícitos: 1) el principio material

${ }^{9}$ El papel que desempeñaron los jesuitas en la formación de los filósofos del «centro» constituye otro aspecto ocultado por el paradigma eurocéntrico. Dussel menciona como ejemplo la instrucción a la que fue sometida Descartes: la constante referencia al jesuita español Francisco Suárez y el estudio de la vertiente dura de la filosofía en la Logica mexicana sive Commentarii in universam Aristotelis Logicam de Antonio Rubio. Sobre esta cuestión, véase: (Dussel, 2010a: 324 ss.).

${ }^{10}$ Este principio material era complementado con un principio formal y un principio de factibilidad ética. A cada uno de ellos le correspondía, además, su principio crítico respectivo (Dussel, 2004: 344 ss.). 
(M) que obliga acerca de la vida de los ciudadanos, 2) el principio formaldemocrático $(\mathrm{L})$ que determina actuar cumpliendo con los procedimientos propios de la legitimidad democrática, y 3) principio de factibilidad (F) que determina operar sólo lo posible. Entre dichos principios se da una mutua y compleja co-determinación sin última instancia (Dussel, 2006: 72-73 y 2009b: 384-385).

Con el entrelazamiento de los principios citados, la filosofía de la liberación propone una nueva arquitectónica con la pretensión de superar las concepciones de las éticas discursivas -Apel y Habermas en particular-y las objeciones al estilo de Rüdiger Bubner y Klaus Gunther referentes al problema de la «aplicación» (Anwendung) de las teorías filosóficas ${ }^{11}$. Frente a la diferenciación entre parte «A» y parte «B» de la ética del discurso de Apel y la distinción entre "principio moral» (Moralprinzip) y "principio democrático» (Demokratieprinzip) del último Habermas ${ }^{12}$, Dussel enfatiza que la legitimidad formal no basta; es necesaria la introducción del principio $m a$ terial protector de la vida humana. Frente a los problemas explicitados por Bubner y Gunther, Dussel responde de tal forma que la siguiente afirmación de Apel queda sin contenido:

Sobre todo a partir de mi polémica con la «ética de la liberación» de Enrique Dussel, orientada esencialmente por la ética del encuentro con el «otro» de Levinas, he llegado a la siguiente convicción escéptica: la orientación primaria de la ética hacia una interacción con los otros no mediada por instituciones [...], más bien podría dificultar la pretendida aplicabilidad concreta de la ética (Apel, 2004: 206).

El principio de factibilidad -inspirado sobre todo por los trabajos epistemológicos de Franz Hinkelammert- garantiza que las coordenadas de la acción política se muevan dentro de la esfera de lo posible, pero yendo más allá de las perspectivas conservadoras. Los horizontes utópicos de la liberación asumen únicamente la función de «modelos de imposibilidad» ${ }^{13}$ (Dussel, 2004: 230-231 y 353).

La conclusión a que nos lleva la arquitectónica dusseliana es la siguiente: el pensamiento latinoamericano habrá de ser construido sobre los pilares constituidos por la negación del eurocentrismo y la adopción de un «giro descolonizador» en el ámbito de la filosofía política. Nuestro locus enun-

${ }^{11}$ El problema aquí era el referente a las instituciones y, en el caso de Klaus Gunther, de la insuficiencia de la «fundamentación» (Bregründung) para la razón práctica. Véanse: (Gunther, 1993: 11 y 33 ss.) y (Bubner, 1989: 75-76 y 79-82).

12 Sobre esta cuestión: (Habermas, 1992: 140).

13 ara un desarrollo de este concepto, resultan indispensables: (Hinkelammert, 2002: 309-310 у 2008: 162-164). 
tiationis nos obliga a tratar los problemas específicos de América Latina, pero siempre en el contexto de un diálogo mundial con otras tradiciones políticas y filosóficas. Se trata de pensar filosóficamente desde un horizonte mundial y hacia un "pluriverso transmoderno» (Dussel, 2007a: 551-552 y 2010b: 135). ¿Hasta qué punto esto es posible?

\section{4. ¿ «Nuevo pensamiento» o etnocentrismo invertido? Una crítica de la filosofía de la liberación}

La era de la postmetafísica ha dado lugar, como parte de sus ambiguas consecuencias, a una serie de concepciones intelectuales de diversa índole. Algunas de ellas han sostenido planteamientos francamente anti-ilustrados. El denominado pensamiento "postmoderno»-producto del deflacionismo del concepto de razón efectuado por las célebres vertientes postwittgenstenianas y postheideggerianas de la filosofía contemporánea- ha jugado un papel fundamental en el desenmascaramiento del carácter eurocéntrico de muchas conceptualizaciones en boga. Al mismo tiempo, ha constituido una reacción a la totalización espacio-temporal de la modernidad globalizante (Koslarek, 1999: 150). La filosofía de la liberación, aun cuando se ha deslindado de las tesis postmodernas ${ }^{14}$, ha criticado al movimiento ilustrado por su categorización autorreferente y su invención del «orientalismo» y el «occidentalismo» respectivos (Dussel, 2010a: 317). No obstante lo anterior, las perspectivas historicistas-relativistas moderadas -Dussel, Rorty y los sociólogos del conocimiento- resultan paradójicas y, por tanto, bastante problemáticas. Como cualquier otro modelo intelectual, poseen tanto ventajas como desventajas. Han permitido, sin lugar a dudas, sacar a la luz el background ideológico y claramente etnocéntrico de diversas propuestas teóricas y filosóficas. A su vez, han posibilitado detectar los cinismos de algunas concepciones políticas actuales. La idea de Cosmópolis como la representación de una comunidad mundial homologada éticamente

${ }^{14}$ En este contexto, resulta conveniente distinguir entre postmodernidad y transmodernidad. La perspectiva postmoderna constituye aquella propia del pensador occidental que, al asumir una postura anti-ilustrada, niega los valores de Occidente poniendo énfasis en el particularismo y culminando en una especie de relativismo ético, epistémico y cultural. La cosmovisión transmoderna coincide con los postmodernos en su crítica a Occidente, pero no comparte su relativismo. Para Dussel, el postmodernismo no aporta una base ética en favor de las víctimas y perdedores de la historia. En cambio, el pensamiento transmoderno sí aporta ese fundamento porque tiene pretensiones de universalidad. 
constituye una de esas ideologías que han justificado intervenciones militares y políticas internacionales de corte colonial ${ }^{15}$.

Sin embargo, las perspectivas historicistas-relativistas sostenidas de manera radical llevan a una destrucción total y autocontradictoria del paradigma occidental y sus aportaciones tanto éticas como cognitivas al planeta entero. Sin negar las pretensiones imperialistas que constantemente han marcado la historia de Occidente, es menester recordar que mucho de lo que nosotros consideramos, hic et nunc, como valioso -los derechos humanos, la democracia, la igualdad, el Estado de derecho, la exigencia de educación para todos, etc.- es producto, querámoslo o no, de la civilización occidental y de un proceso de aprendizaje que ha sabido retomar de otras tradiciones contenidos normativos indispensables ${ }^{16}$.

En este contexto, la concepción «transmoderna» sostenida por la filosofía de la liberación puede identificarse con el rubro de etnocentrismo invertido. Esta modalidad de pensamiento se caracteriza por los siguientes aspectos:

1.- Desde una perspectiva epistemológica, la postura dusseliana representa una crítica a Occidente mediante, precisamente, categorías occidentales. En primer lugar, se desarrolla un análisis típicamente filosófico-europeo prácticamente de todas sus problemáticas: ya sea en términos de "crítica» (Marx y la primera generación de la Escuela de Frankfurt), «destrucción» (Heidegger), «deconstrucción» (Derrida) o «reconstrucción»(Habermas), las herramientas analíticas principalmente utilizadas son aquellas desarrolladas por los modelos postmetafísicos característicos del siglo XX. Es por esta razón que los diversos elementos de la metodología de la filosofía de la liberación son fácilmente identificables. Por mencionar un ejemplo: la idea de comunidad intersubjetiva le viene a Dussel de la tradición alemana; detrás

${ }^{15}$ Sobre esta cuestión: (Mendieta, 2010: 297 ss.) y (Zolo, 2000: 17, 30 y 137 ss.).

${ }^{16}$ En este sentido, estoy de acuerdo con Alasdair MacIntyre en la tesis de que cada teoría de la justicia se sostiene en un tipo de racionalidad específico. Las rivalidades y desacuerdos respecto de las teorías de la justicia se debe a que expresan tradiciones que se encuentran encarnadas en tipos particulares de relación social. Sin embargo, considero que la total relativización de los modelos de justicia llevan a una «autocontradicción performativa» (performativer Selbstwiderspruch) en virtud de que niega precisamente lo que presupone: la universalidad moral. En lo referente a la primera tesis, véase: (MacIntyre, 1988: 1-9 y 389). La importancia del pensamiento semita, del cristianismo, de los jesuitas, del pensamiento latino e italiano, de la tradición del Corpus Iuris Civilis, etc., constituyen ejemplos de contenidos normativos absorbidos por Occidente, los cuales, desgraciadamente, no siempre han sido expuestos como tales. La tradición occidental, en este sentido, no ha sido completamente autorreferente. 
de ella se encuentran el último Husserl y, evidentemente, Apel y Habermas. Así, la Diskursethik deviene una parte central de la arquitectónica de la filosofía de la liberación. En segundo lugar, la crítica a Occidente adquiere tintes radicales y autocontradictorios: niega sus contenidos conceptuales, normativos y epistémicos -el individualismo, el ideal científico de la Ilustración, su autocomprensión histórica, su entendimiento de las temáticas filosóficas, etc.- desenmascarándolos como intentos de «imperialismo cultural», pero al propio tiempo los utiliza, de manera explícita o implícita, en la construcción de un modelo alternativo. Esto conduce a una situación paradójica: el «colonialismo mental» que explícitamente se pretende expulsar de los planteamientos filosóficos latinoamericanos se conserva como background implícito en la edificación anti-occidental del pensamiento dusseliano.

2.- Desde un punto de vista explicativo, la filosofía de la liberación hace de Latinoamérica un referente descontextualizado en virtud del arsenal categorial elegido para su elucidación. Por una parte, se emplea el aparato conceptual occidental tanto clásico -expresado en palabras griegas y latinas- como moderno - "poder», «Estado», «legitimidad», «factibilidad», "acontecimiento", etc.- que asume las funciones de prisma hermenéutico que hace posible una moral y una ética "comparadas»; por otra, se determina el valor de las culturas no-occidentales por analogía a Occidente y sus contenidos normativos centrales. Esto se manifiesta claramente en el tratamiento que hace Dussel de diversas culturas antiguas al utilizar argumentos per analogiam para determinar su validez tanto ética como epistémica. Así, el mundo prehispánico o el chino-tradicional no aparecen como culturas con especificidades inconmensurables respecto a Occidente, sino como espejos de la cosmovisión occidental griega al compartir criterios y problemáticas comunes. Es por este motivo que expresiones como «filosofía», "lógos» o "ethos» se someten a una interpretación extensiva y se aplican indiscriminadamente a modelos culturales que, prima facie, se autocomprenden con categorías distintas a las propias del paradigma filosófico occidental. Esto conduce a otra situación paradójica: explícitamente se admite que los planteamientos de Occidente están francamente equivocados, pero al propio tiempo se explica y evalúa positivamente a todas las demás culturas a través de las gafas hermenéuticas y categoriales desarrolladas por el mismo modelo que se considera errado. Porfirio Miranda, al abordar una temática ligada a la anterior, precisaba:

Quienes esgrimen rasgos laudables de otras culturas no suelen percatarse de que es la herencia occidental el criterio firme en virtud del cual encuentran laudables tales rasgos. [...] Aprovecho la ocasión para confesar que el ataque de mi Marx y la Biblia 
contra la cultura occidental, sin ser desacertado, era un ataque tonto, y por tanto injusto. Tonto porque criticaba a Occidente basándose precisamente en los criterios heredados de Occidente (Miranda, 1996: 31).

La idea dusseliana de que todas las tradiciones culturales poseen una serie de «núcleos problemáticos universales» está contaminada por el presupuesto germánico erróneo de que la filosofía tiene un papel central en el mundo intelectual y, por extensión, en todas las prácticas sociales ${ }^{17}$. En el caso de Latinoamérica, Dussel ha pretendido construir una identidad y especificidad inexistente que vale, precisamente, porque posee los contenidos de Occidente, i.e., el «pensamiento filosófico», y al mismo tiempo se distingue de ellos en virtud de sus peculiaridades ${ }^{18}$. El «eurocentrismo invertido» llega así a su máxima expresión: en lugar de determinar la importancia de las culturas no-occidentales -o no occidentales in toto- a través de sus particularidades, la misma se establece sobre la base de una analogía encubierta referente a un elemento del mundo occidental, i.e., la filosofía. De ahí la desesperada insistencia en la construcción de una «tradición filosófica» latinoamericana -de manera análoga a las ya clásicas tradiciones occidentales «continentales» y «anglosajonas»-. Es por esta razón que, en la filosofía de la liberación, la verdadera «Latinoamérica» aparece deformada la mayoría de las veces.

3.- Desde una óptica política, la filosofía de la liberación -en sus pretensiones "postcoloniales»- puede conducir a actitudes de reacción alarmantes. En una situación extrema, conlleva a identificar toda apelación a Occidente como un intento de imperialismo cultural de los países del «Norte». Y esto tiene consecuencias graves. En primer lugar, se hace patente un déficit en la comprensión de las reivindicaciones latinoamericanas: éstas no se plantean en términos de la postcolonialidad sino en el lenguaje «occidental» de los derechos humanos. No debe sorprender, por tanto, que la exclusión tradicional de niños, mujeres, indígenas y homosexuales en la región sea combatida a través de movilizaciones cuyos reclamos se basan en el reconocimiento de sus derechos universales, de manera paralela al establecimiento de procedimientos garantistas -inventados en Occidente- para la protección efectiva de los mismos ${ }^{19}$. Por consiguiente, no resulta nada ex-

\footnotetext{
${ }^{17}$ Esta es una observación que hace Richard Rorty a Habermas. Véase: (Rorty, 1993: 119).

${ }^{18}$ Esto es aplicable, mutatis mutandis, a todas las demás tradiciones no-occidentales.

${ }^{19}$ En este punto pueden señalarse como ejemplos los controles de constitucionalidad concentrados y difusos que han adquirido tanta importancia en nuestros países. Esto ha tenido como consecuencia que, en el ámbito de la filosofía del derecho en América Latina, el paradigma dominante en la materia sea el constitucionalismo, ya sea en su vertiente "garantista» (Ferrajoli) o "principialista» (Dworkin, Alexy, Zagrebelsky).
} 
traño que las propuestas de superación de los problemas de marginación y miseria en que viven los indígenas en México no sean expuestas en términos academicistas vinculados al pensamiento «transmoderno» o de las «epistemologías del Sur», sino como una extensión de los beneficios proporcionados por el Estado democrático-constitucional a los ciudadanos medios. Así, los reclamos de autonomía han quedado en segundo plano frente a la necesidad imperante de leyes y políticas públicas que hagan posible la inclusión de los indígenas a proyectos estatales que impliquen un aumento de sus prerrogativas $-v$. gr., educación, empleo y suministro de medicinas occidentales para que no mueran de enfermedades curables-. El paradigma de la "acción afirmativa» (affirmative action), i.e., de aquellos mecanismos que tienen por objeto la inclusión de individuos tradicionalmente discriminados, ha tenido en este contexto aplicaciones favorables. En segundo lugar, resulta conveniente enfatizar que la aproximación postcolonial a los problemas de nuestra región adquiere un status de idealización y de justificación de prácticas contrarias a los derechos humanos. En este punto, la filosofía de la liberación comparte el prejuicio propio de los anti-globalistas de que debe revalorarse las identidades étnico-nacionales y entender la diferenciación cultural como un "patrimonio antropológico evolutivamente precioso" (Zolo, 2000: 14). Pero el problema aquí es el siguiente: si se coloca la diferencia cultural por encima de los derechos de los individuos, cualquier intento de «liberación» fracasa necesariamente. La identificación de Fidel Castro o de Hugo Chávez como «signos de esperanza» para Latinoamérica (Dussel, 2006: 7) no nos deja dudas de que la filosofía de la «liberación» puede canalizar los movimientos sociales hacia su opuesto, i.e., la opresión. ¿Qué significa, por tanto, que los pueblos latinoamericanos se «liberen» de las instituciones occidentales básicas? En esta forma de entender las cosas, quienes realmente quedan liberados no son los individuos latinos de carne y hueso, sino precisamente los gobernantes de la región. En nombre de la comunidad, la identidad y la diferencia, las autoridades políticas quedan desvinculadas de cualquier tipo de control y límite del poder, dejando a los individuos en un trágico estado de indefensión. Esto nos conduce a una última paradoja: la filosofía de la liberación, de ser llevada a la práctica, no conduciría a la "emancipación» de los pueblos y a la inclusión de las víctimas, sino a la imposición autoritaria y excluyente resultante de la liberación de los gobernantes latinoamericanos de cualquier control real de su proceder. En otras palabras: la liberación de la «comunidad» equivale a su libertad incondicionada para ultrajar al individuo. 


\section{Conclusión}

¿Todo esto significa que no es posible un pensamiento «filosófico» especificamente latinoamericano? No precisamente. Lo que pretendo poner de manifiesto es que América Latina es una síntesis de una variedad de expresiones políticas, jurídicas, culturales, artísticas y académicas no reductibles a una tradición filosófica "originaria». Nuestra región pertenece a Occidente y al mismo tiempo constituye una cultura mestiza con raíces tradicionales. De ahí las disonancias cognitivas que se han producido en la región por la introducción de instituciones progresistas propias del mundo occidental -pienso, por ejemplo, en el reconocimiento institucional de los matrimonios entre personas del mismo sexo-. Pero de la misma manera que las culturas prehispánicas no son un espejo de la Grecia clásica, Latinoamérica no es un espejo de la academia filosófica europea. Lo que hace valioso al pensamiento de América Latina es, justamente, que no es puramente "filosófico» en el sentido europeo de la palabra. No requerimos acudir a la tradición filosófica como parámetro evaluador de la relevancia de nuestros productos culturales. En su lugar, prefiero afirmar que de lo que se trata es de abrir nuestra reflexión -tal y como efectivamente se ha hecho- a movimientos sociales e intelectuales que no necesariamente tienen una matriz cultural o racional común. No necesitamos a un Kant o a un Hegel «latinoamericanos» justamente porque no somos alemanes, no pensamos como alemanes, i.e., «filosóficamente», y vivimos en un contexto que exige, más que una «nueva» tradición filosófica, una continua meditación acerca de las posibles salidas a nuestras problemáticas más apremiantes: marginación, pobreza, corrupción, violación sistemática de derechos humanos, atraso tecnológico y educativo, etc. La reducción de la política a la filosofía propia del síndrome platónico (Salazar, 1997: 15) debe ser descartada de manera definitiva de nuestro pensamiento. En su lugar, debe haber una comprensión de que la verdadera esperanza de nuestra especie no está en los particularismos postcoloniales y en las etiquetas culturales - "yo soy latino", "tú eres europeo», etc.-, sino en la construcción de un futuro auténticamente inclusivo y cosmopolita.

\section{Bibliografía}

Apel, Karl-Otto (2002), Semiótica trascendental y filosofía primera. Madrid: Síntesis.

Apel, Karl-Otto (2004), Apel versus Habermas. Granada: Comares. 
Badiou, Alain (1999), El ser y el acontecimiento. Buenos Aires: Manantial. Barber, Michael (1998), Ethical hermeneutics. Rationalism in Enrique Dussel's philosophy of liberation. Nueva York: Fordham University Press.

Benhabib, Seyla (1992), Situating the self. Gender, community and postmodernism in contemporary ethics. Nueva York: Routledge.

Bernstein, Richard (1983), Beyond objectivism and relativism. Science, hermeneutics and praxis. Filadelfia: University of Pennsylvania Press.

Bubner, Rüdiger (1989), "Racionalidad, forma de vida e historia", en Daimon. Revista internacional de filosofía, num. 1, 1989. España: Universidad de Murcia, pp. 75-86.

Derrida, Jacques (1971), De la gramatología. México: Siglo XXI.

Derrida, Jacques (1989), La escritura y la diferencia. Barcelona: Anthropos.

Dussel, Enrique (1969), El humanismo semita. Estructuras intencionales radicales del pueblo de Israel y otros semitas. Buenos Aires: Eudeba.

Dussel, Enrique (1995), The invention of the Americas. Eclipse of «the Other» and the myth of modernity. Nueva York: Continuum.

Dussel, Enrique (1997), Filosofía de la liberación. México: Edicol.

Dussel, Enrique (1998a), Ética de la liberación en la edad de la globalización y de la exclusión. Madrid: Trotta.

Dussel, Enrique (1998b), "En busca del sentido (origen y desarrollo de una filosofía de la liberación)", en Anthropos, num. 180, septiembre-octubre 1998. Barcelona: Proyecto A Ediciones, pp. 13-36.

Dussel, Enrique (2004), Ética del discurso y ética de la liberación. Madrid: Trotta.

Dussel, Enrique (2006), 20 tesis de politica. México: Siglo XXI.

Dussel, Enrique (2007a), Política de la liberación. Historia mundial y crítica. Madrid: Trotta.

Dussel, Enrique (2007b), Materiales para una política de la liberación. México: Plaza y Valdés.

Dussel, Enrique (2009a), "Introducción”, en Enrique Dussel, Eduardo Mendieta, Carmen Bohórquez, El pensamiento filosófico latinoamericano, del Caribe y "latino" (1300-2000). México: Siglo XXI, pp. 15-20.

Dussel, Enrique (2009b), Política de la liberación. Vol. II. Arquitectónica. Madrid: Trotta.

Dussel, Enrique (2010a), "Meditaciones anti-cartesianas: Sobre el origen del anti-discurso filosófico de la modernidad”, en Ileana Rodríguez y Josebe Martínez (comp.), Estudios transatlánticos postcoloniales. I. Narrativas comando/sistemas mundos: colonialidad/modernidad. Barcelona: Anthropos/UAM Iztapalapa, pp. 317-372. 
Dussel, Enrique (2010b), "El siglo XXI: Nueva edad en la historia de la filosofía en tanto diálogo mundial entre tradiciones filosóficas”, en Signos Filosóficos, vol. XII, num. 23, enero-junio 2010. México: UAM Iztapalapa, pp. 119-140.

Gadamer, Hans-Georg (2007), El giro hermenéutico. Madrid: Cátedra.

Grondin, Jean (2006), Introducción a la metafísica. Barcelona: Herder.

Günther, Klaus (1993), The sense of appropriateness. Application discourses in morality and law. Albania: State University of New York Press.

Habermas, Jürgen (1990), Pensamiento postmetafísico. Barcelona: Paidós. Habermas, Jürgen (1992), Faktizität und Geltung. Beiträge zur Diskurstheorie des Rechts und des demokratischen Rechtsstaats. Frankfurt am Main: Suhrkamp.

Hall, David (2000), "La China moderna y el occidente postmoderno", en Eliot Deutsch (comp.), Cultura y modernidad. Perspectivas filosóficas de Oriente y Occidente. Barcelona: Kairós, pp. 67-87.

Hinkelammert, Franz (2002), Crítica de la razón utópica. Bilbao: Desclée de Brouwer.

Hinkelammert, Franz (2008), Hacia una crítica de la razón mítica. El laberinto de la modernidad. México: Dríada.

Joseph, George (2009), "Mathematics and eurocentrism", en Rajani Kannepalli Kanth (comp.), The challenge of eurocentrism: Global perspectives, policy and prospects. Nueva York: Palgrave Macmillan, pp. 25-44. https://doi.org/10.1057/9780230620896_3

Koslarek, Oliver (1999), "Liberación como acción. Una lectura sociológica de la ética de la liberación”, en Polis, num. 98, diciembre 1999. México: UAM Iztapalapa, pp. 119-156.

Levinas, Emmanuel (1977), Totalidad e infinito. Ensayo sobre la exterioridad. Salamanca: Sígueme.

Lyotard, Jean-François (2008), La condición postmoderna. Madrid: Cátedra. MacIntyre, Alasdair (1988), Whose justice? Which rationality?. Indiana: University of Notre Dame Press.

Marchart, Oliver (2009), El pensamiento político postfundacional. La diferencia politica en Nancy, Lefort, Badiou y Laclau. Buenos Aires: Fondo de Cultura Económica.

Mazrui, Ali (2009), "Foreword: The seven biases of eurocentrism: A diagnostic", en Rajani Kannepalli Kanth (comp.), The challenge of eurocentrism: Global perspectives, policy and prospects. Nueva York: Palgrave Macmillan, pp. xi-xix.

Medina, Jorge (2010), ¿El mesías soy yo? Introducción al pensamiento de Emmanuel Levinas. México: Jus. 
Mendieta, Eduardo (2010), "Del cosmopolitismo imperial al cosmopolitismo dialógico: Humildad, solidaridad y paciencia", en Ileana Rodríguez y Josebe Martínez (comp.), Estudios transatlánticos postcoloniales. I. Narrativas comando/sistemas mundos: colonialidad/modernidad. Barcelona: Anthropos/UAM Iztapalapa, pp. 293-315.

Miranda, José Porfirio (1996), Racionalidad y democracia. Salamanca: Sígueme.

Pannenberg, Wolfhart (2002), Una historia de la filosofía desde la idea de Dios. Teología y filosofía. Salamanca: Sígueme.

Rorty, Richard (1979), Philosophy and the mirror of nature. Princeton: Princeton University Press.

Rorty, Richard (1993), "Intersubjetividad y libertad (entrevista)", en Teoría. Revista de Filosofía, año 1, num. 1, julio 1993. México: UNAM/ Facultad de Filosofía y Letras, pp. 113-122.

Salazar, Luis (1997), El sindrome de Platón. ¿Hobbes o Spinoza?. México: UAM Azcapotzalco.

Scannone, Juan Carlos (2005), Religión y nuevo pensamiento. Hacia una filosofía de la religión para nuestro tiempo desde América Latina. Barcelona: Anthropos/UAM-I.

Schelkshorn, Hans (1992), Ethik der Befreiung. Einführung in die philosophie Enrique Dussels. Viena: Herder.

Searle, John (2003), "Philosophy in a new century", en Journal of Philosophical Research, APA centennial supplement, 2003. Indiana: APA, pp. 3-22.

Van Riessen, Renée (2007), Man as a place of God. Levinas' hermeneutics of kenosis. Holanda: Springer. https://doi.org/10.1007/978-1-40206228-5

Vattimo, Gianni (1994), El fin de la modernidad. Nibilismo y hermenéutica en la cultura postmoderna. Barcelona: Planeta-Agostini.

Vattimo, Gianni (2001), “Metafísica, violencia, secularización”, en Gianni Vattimo (comp.), La secularización de la filosofía. Hermenéutica y posmodernidad. Barcelona: Gedisa, pp. 63-88.

Vattimo, Gianni (2010), Después de la muerte de Dios. Conversaciones sobre religión, politica y cultura. Buenos Aires: Paidós.

Waldenfels, Bernhard (2010), "Es gibt Ordnung / Il y a de l'ordre / Hay orden”, en Ramón Alvarado, Gustavo Leyva, Sergio Pérez (comp.), ¿Existe el orden? La norma, la ley y la transgresión. Barcelona: Anthropos/UAM Iztapalapa, pp. 25-42.

Zolo, Danilo (2000), Cosmópolis. Perspectiva y riesgos de un gobierno mundial. Barcelona: Paidós. 